\title{
FOCOS DE CALOR NA BACIA HIDROGRÁFICA DO RIO POTI (CEARÁ/PIAUÍ) A PARTIR DOS REGISTROS DO SATÉLITE NOAA-18
}

\author{
Emanuel Lindemberg Silva Albuquerque ${ }^{(a)}$ \\ (a) Coordenação do Curso de Geografia, Universidade Federal do Piauí, lindemberg @ufpi.edu.br
}

Eixo: GEOTECNOLOGIAS E MODELAGEM ESPACIAL EM GEOGRAFIA FÍSICA

\begin{abstract}
Resumo
Desde os primórdios da civilização humana e, expressivamente, com a ocupação empreendida pelos colonizadores, as queimadas vêm sendo utilizadas, sobretudo, para o preparo da terra e/ou criação de animais. O estudo objetiva realizar uma análise têmporo-espacial das ocorrências de focos de calor na bacia hidrográfica do Rio Poti (Ceará/Piauí) nos anos de 2010, 2013 e 2016, almejando quantificar e qualificar esses dados dentro do contexto progressivo e/ou regressivo. Os procedimentos metodológicos contemplam revisão bibliográfica e aquisição da base cartográfica, inseridas em ambiente de Sistema de Informação Geográfica. Utilizaram-se os registros do satélite NOAA-18 (National Oceanic Atmospheric Administration), obtidos no Banco de Dados de Queimadas (BDQueimadas-INPE). Conclui-se que houve um aumento considerável nos focos de calor nos anos trabalhados, totalizando 2.380 registros, sendo que os maiores ocorrências se concentraram no mês de outubro, com respectivamente 11, 226 e 963 focos.
\end{abstract}

Palavras chave: Geotecnologias, Queimadas, Semiárido.

\section{Introdução}

Desde os primórdios da civilização humana e, expressivamente, com a ocupação empreendida pelos colonizadores, ocorreu uma superexploração dos recursos naturais, sobretudo da cobertura vegetal, sequenciado, em muitas ocasiões, pelo uso predatório e indiscriminado das queimadas (GOMES et al., 2010). Destaca-se que esta tradição secular, sobretudo no ambiente semiárido, é utilizada para a limpa e, consequentemente, para o plantio e/ou para a criação de animais.

Ao considerar as características fisionômicas e florísticas do Nordeste brasileiro, aliada a alta fragilidade e vulnerabilidade dos sistemas ambientais frente aos processos de uso e ocupação da terra (SOUZA, 2000), nota-se a priori uma maior incidência de queimadas e incêndios florestais, consequentemente, na ocorrência de focos de calor, que foram registrados na última década do século XXI, sequenciado ainda pelas secas recorrentes, a exemplo do período 2010/2016.

De acordo com Silva Filho et al. (2009), as queimadas correspondem a uma técnica de preparo do solo, que utiliza a aplicação do fogo para a limpeza do terreno. Por sua vez, o termo foco de calor é utilizado 


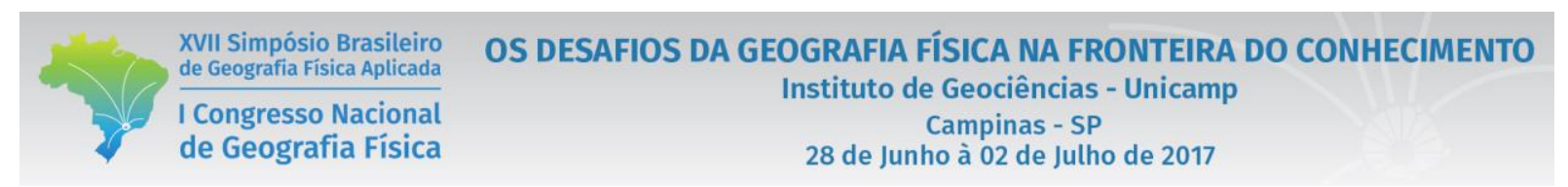

para o registro da ocorrência do fogo na superfície terrestre, obtido por meio das técnicas de sensoriamento remoto.

A importância da detecção das queimadas transcende a ocorrência dos focos de calor em si, uma vez que o sensoriamento remoto orbital constitui um importante sistema de monitoramento ambiental, sobretudo quando associado ao mapeamento de incêndios florestais e na identificação de áreas desmatadas (FLORENZANO, 2007).

Nesse sentido, Jensen (2009) define que o sensoriamento remoto é a arte e a ciência de obter informações de um objeto sem estar em contato físico com ele, podendo ser usado para medir e monitorar importantes características biofísicas e atividades humanas na Terra, por meio da captação da radiação eletromagnética refletida e emitida pela superfície, a exemplo dos focos de calor.

Portanto, objetiva-se no estudo realizar uma análise têmporo-espacial das ocorrências de focos de calor na bacia hidrográfica do Rio Poti (Ceará/Piauí) nos anos de 2010, 2013 e 2016, almejando quantificar e qualificar esses dados dentro do contexto progressivo e/ou regressivo, na perspectiva de configurar cenários tendenciais e potencializar a tomada correta de decisões por parte dos órgãos competentes.

A bacia hidrográfica que compreende o recorte espacial da pesquisa encontra-se inserida em estruturas do embasamento cristalino Pré-Cambriano (alto curso), no estado do Ceará, e em setores da bacia sedimentar do Parnaíba, médio e baixo curso fluvial, no estado do Piauí (ALBUQUERQUE e LIMA, 2016). Destacase que a bacia hidrográfica compõe um sistema, no qual a relação entre os diferentes componentes formam uma paisagem peculiar, marcada por uma dinâmica específica, em que os seus componentes não se limitam aos elementos naturais, mas envolvem também a sociedade (ZANELLA et al., 2013).

O estudo empreendido almeja identificar os setores espaciais que possuem uma maior incidência de focos de calor para os anos em estudo, possibilitando uma abordagem regional no tocante a realização de ações por parte dos governos e dos órgãos competentes do Ceará e Piauí, tendo em vista que a bacia hidrográfica em epígrafe drena área dos dois Estados.

\section{Materiais e Métodos}

\section{Área de estudo}

A bacia hidrográfica do Rio Poti (Figura 1) apresenta uma área de aproximadamente $52.270 \mathrm{~km}^{2}$, dos quais $38.797 \mathrm{~km}^{2}$ encontram-se no estado do Piauí e $13.473 \mathrm{~km}^{2}$ no estado do Ceará, sendo que o canal principal deste rio possui cerca de $538 \mathrm{~km}$ de extensão (nascente/foz). Salienta-se que o Rio Poti é um dos grandes afluentes do Rio Parnaíba, eixo principal da drenagem piauiense. Não obstante, corrobora-se que 
a Região Hidrográfica do Parnaíba integra também as áreas limítrofes do Maranhão (porção oeste) e um setor espacial no Ceará (ao leste), conforme pode ser visualizado na figura 2.

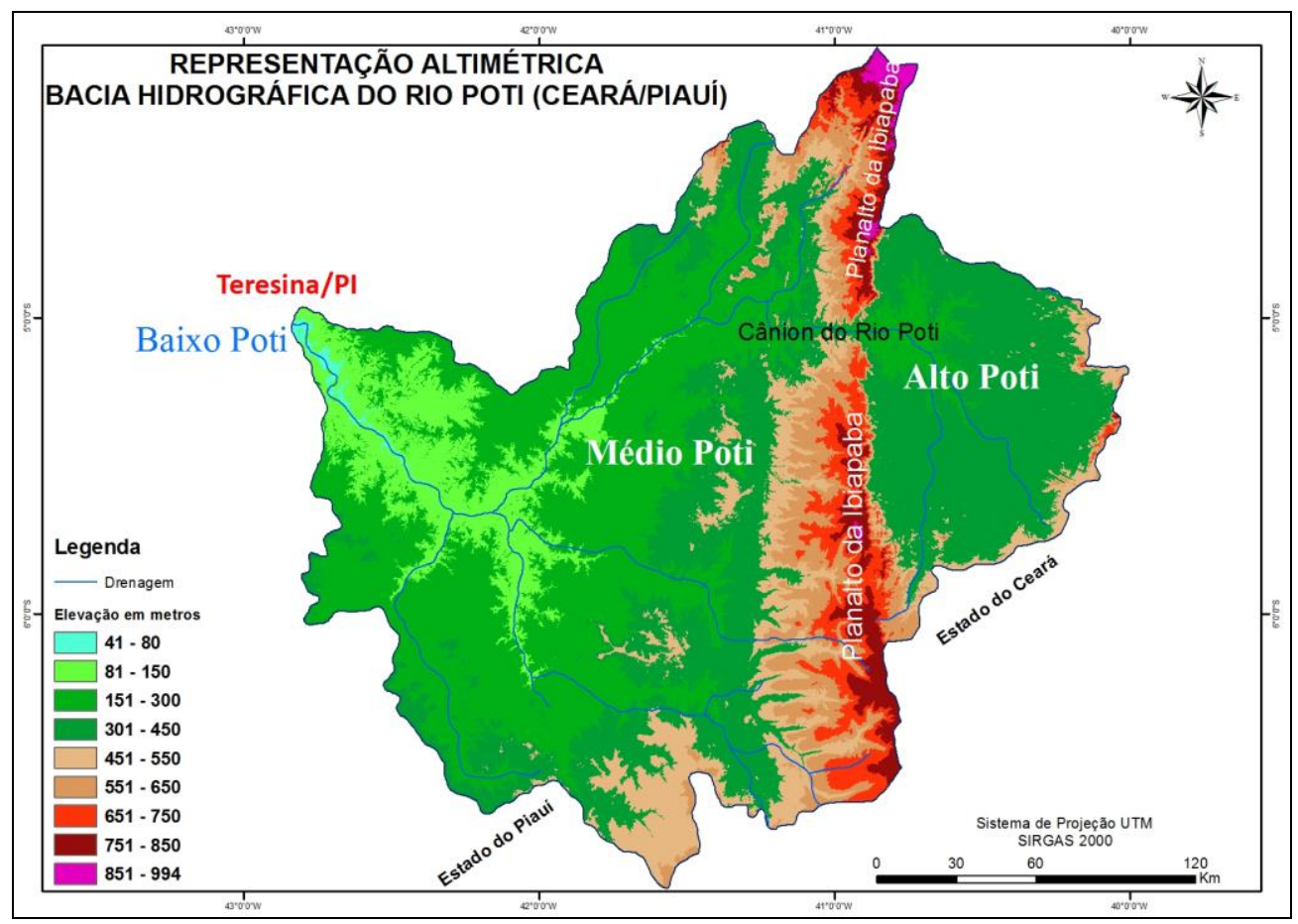

Figura 1 - Representação altimétrica da bacia hidrográfica do Rio Poti (Ceará/Piauí)

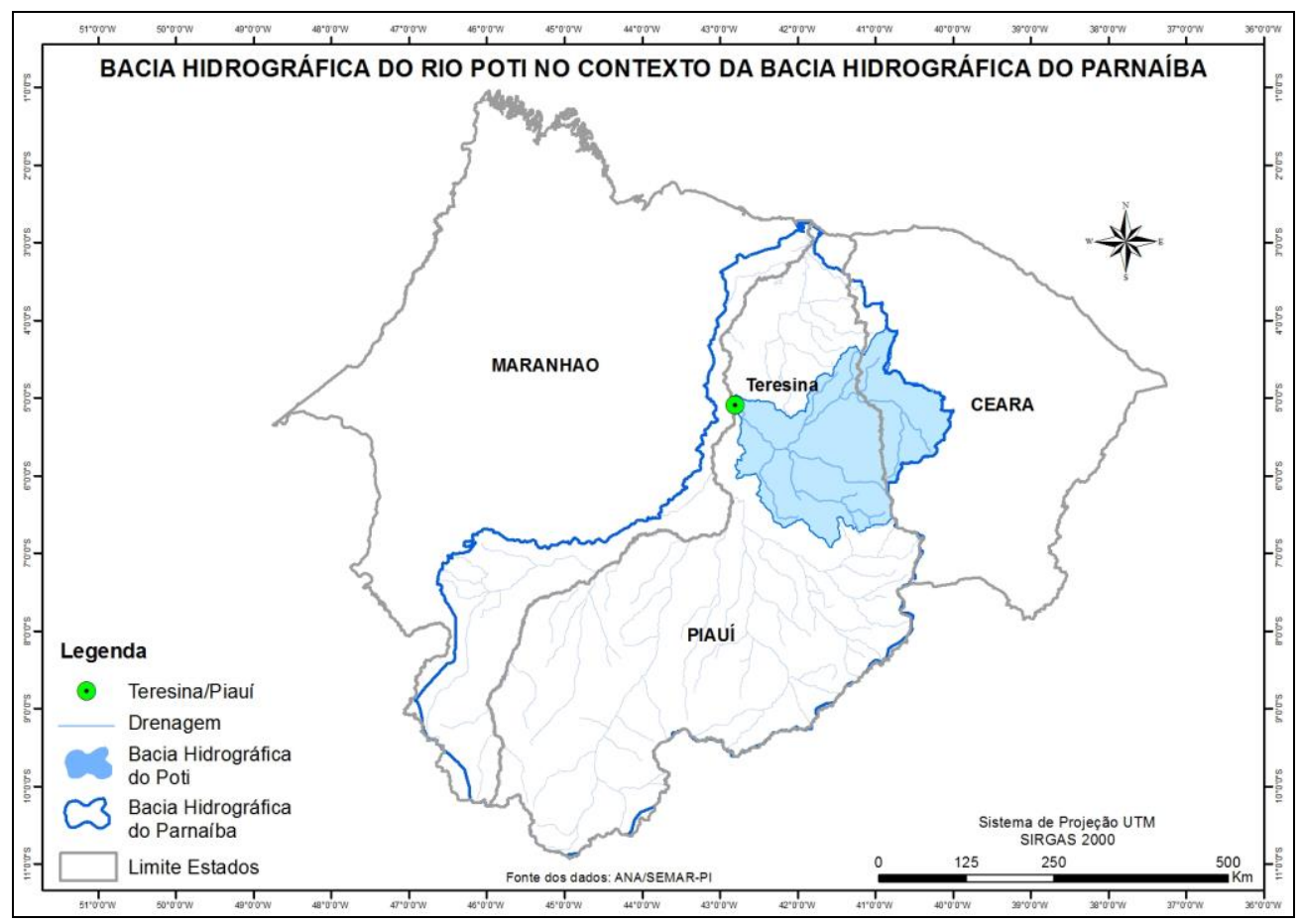

Figura 2 - Bacia hidrográfica do Rio Poti no contexto da bacia hidrográfica do Rio Parnaíba 


\section{OS DESAFIOS DA GEOGRAFIA FÍSICA NA FRONTEIRA DO CONHECIMENTO \\ Instituto de Geociências - Unicamp \\ Campinas - SP \\ 28 de Junho à 02 de Julho de 2017}

As cabeceiras principais do Rio Poti encontram-se no estado do Ceará, com destaque para a nascente localizada na Fazenda Jatobá, no município de Quiterianópolis, sendo que seu alto curso fluvial engloba, no todo ou em partes, os municípios cearenses de: Ararendá, Crateús, Croatá, Guaraciaba do Norte, Independência, Ipaporanga, Ipueiras, Nova Russas, Novo Oriente, Poranga, Quiterianópolis e Tamboril, num setor espacial na Depressão Periférica à Bacia Sedimentar do Parnaíba (ALBUQUERQUE e LIMA, 2016).

Ao analisar o mapa que trata da representação altimétrica da bacia hidrográfica em pauta, constata-se níveis mais significativos (cota acima de 800 metros) no trecho da divisa interestadual Ceará/Piaú e que configura, do ponto de vista geomorfológico, o Planalto da Ibiapaba (SOUZA, 2000). Essa característica é justificada pelo princípio geológico da isostasia, ou seja, em que houve o soerguimento da borda oriental da Bacia Sedimentar do Parnaíba, dando origem a um relevo tido como cuestiforme, marcado por uma vertente íngreme (borda leste) e um reverso suave (porção ocidental).

Como produto do fator geológico e climático, em associação aos outros fatores ambientais, a drenagem presente na bacia hidrográfica do Rio Poti apresenta certas particularidades, sendo que no alto curso o padrão fluvial se arranja numa densa rede de pequenos tributários que descem as encostas, apresentando pequenas amplitudes altimétricas em seus perfis longitudinais e em pequenas extensões alcançam o nível de base geral do amplo pediplano cristalino, abaixo de 300 metros de altitude, executando-se os cursos d'água que moldam o front da Ibiapaba (Relevo de Cuesta) e que são os responsáveis pelo retalhamento desta escarpa (LIMA, 1982).

No tocante à conformação geral dessa bacia hidrográfica, uma assimetria digna de realce é observada na seção transversal entre o alto e médio curso fluvial (área de entorno da divisa interestadual Ceará/Piauí), em que o mesmo se encontra entalhado numa falha geológica (sistema de lineamentos regionais do Transbrasiliano) que secciona transversalmente o Planalto da Ibiapaba (PFALTZGRAFF et al., 2010). Este setor espacial forma uma região de rara beleza cênica e que representa o Cânion do Rio Poti, num trecho que se estende por mais de $100 \mathrm{~km}$ (entre o alto e baixo cânion) e que engloba os municípios de Crateús/CE, Buriti dos Montes/PI, Castelo do Piauí/PI e Juazeiro do Piauí/PI (PIAUÍ, 2010).

No trecho entre o médio e baixo curso fluvial, até sua foz no Rio Parnaíba, em Teresina, capital do estado do Piauí, o mesmo segue um padrão uniforme de drenagem, com intercalações mais perceptíveis derivadas das sucessivas alterações entre as camadas geológicas que compõem essa bacia sedimentar, tendo em vista que há um caimento topográfico (sentido Leste-Oeste) suave das camadas geológicas em direção à calha principal do Rio Parnaíba. 


\section{Procedimentos metodológicos e operacionais}

Os procedimentos metodológicos para a análise e caracterização dos focos de calor tiveram início com o levantamento bibliográfico e cartográfico da área em estudo. O levantamento bibliográfico permitiu identificar e avaliar a melhor metodologia, considerando as particularidades do recorte espacial da pesquisa, destacando as contribuições de: ASSAD \& SANO (1998); NOVO (1998); ROCHA (2000); FERREIRA (2004), FLORENZANO (2007), GOMES et al., (2010), entre outros.

Foram utilizados os dados do satélite NOAA-18 (National Oceanic and Atmospheric Admnistration), que é equipado pelo sensor Advanced Very High Resolution Radiometer (AVHRR), ou seja, um Radiômetro Avançado de Resolução Muito Alta, possuindo um resolução espacial de 1 x $1 \mathrm{~km}$, tendo uma banda do infravermelho sensível a variação de temperatura.

Vale mencionar que a escolha do satélite NOAA-18 é justificada pela precisão na captura dos dados, uma vez que a órbita deste satélite passa no trecho que compreende o recorte espacial da pesquisa a partir das 18:00h, ou seja, abrangendo o horário noturno. É importante ressaltar que o sensor AVHRR não irá detectar focos de incêndios e sim focos de calor, ou seja, tudo que está sobre a superfície terrestre que possui uma temperatura superior a $47^{\circ} \mathrm{C}$. Como a captura dos registros é realizada a noite, a probabilidade de se confirmar o incêndio é quase que certa.

É válido lembrar que somente frentes de fogo com mais de 30 metros de diâmetro são passíveis de serem detectadas pelo sensor, e que a presença de nuvens e o sombreamento das árvores interferem diretamente na deteç̧ão dos focos calor. Deste modo, salienta-se que a quantidade de focos de calor detectada representa apenas uma fração da real ocorrência (SILVA FILHO et al., 2009), mas corroborando que estes dados são os que mais se aproxima da realidade dentro do escopo temporal da pesquisa.

De acordo com Florenzano (2007), as imagens do satélite NOAA, através do sensor AVHRR, são muito utilizadas para detectar focos de incêndio, uma vez que este permite identificar e localizar, em tempo real, focos de fogo ativo em todo o território brasileiro, respeitando as configurações de captura por sensoriamento remoto, tendo em vista que é um satélite do tipo polar de baixa altura.

O satélite mencionado possui múltiplos usos, dentre os quais: i) avaliar a distribuição da temperatura sobre o mar e a terra; ii) indicar condições meteorológicas e agrometeorológicas; iii) identificar área queimada por meio dos canais adicionais (região do visível e infravermelho) e; iv) monitorar queimadas, mostrandose muito útil na identificação das ocorrências dos focos de calor, considerando os princípios e as resoluções (espacial, temporal, radiométrica e espectral) do sensoriamento remoto orbital. 
Os dados georreferenciados foram obtidos através de download no site do Instituto Nacional de Pesquisas Espaciais (INPE), através do Banco de Dados de Queimadas (BRASIL, 2017), em formato shapefile. Procedeu-se na sequência com a: 1) Reprojeção dos dados ao sistema UTM / SIRGAS 2000; 2) Criação do banco de dados geográfico (BDFocosCalor) em formato shapefile com geometria pontual; 3) Tabulação dos dados (NOAA-18) para o recorte espacial da pesquisa; 4) Quantificação mensal e anual dos registros e; 5) Espacialização e geração dos mapas de focos de calor para os anos de 2010, 2013 e 2016, considerando todos os registros obtidos entre o dia $1^{\circ}$ de janeiro a 31 de dezembro de cada ano em análise.

Salienta-se que o mapeamento dos focos de calor foi realizado em ambiente de Sistema de Informação Geográfica (SIG), utilizando recursos dos softwares QGIS 2.18.3 (plataforma livre) e ArcGIS 10.2 (com licença registrada na Universidade Federal do Piauí - UFPI).

\section{Resultados e Discussões}

$\mathrm{Na}$ perspectiva de realizar a análise têmporo-espacial das ocorrências de focos de calor na bacia hidrográfica do Rio Poti (Ceará/Piauí) nos anos de 2010, 2013 e 2016, e no intuito de quantificar e qualificar as informações obtidas dentro do contexto progressivo e/ou regressivo, os dados vetoriais das ocorrências foram processados em ambiente SIG, atrelado ao banco de dados geográfico que foi estruturado. Feita esta etapa, constatou-se um total de 2.380 focos de calor na bacia hidrográfica em pauta, no somatório dos três anos em destaque, a saber: 2010, com 62 registros; 2013, com 416 registros e; 2016, com 1.902 registros.

Ao avaliar o ano de 2010 (Figura 3), constata-se que as ocorrências dos focos de calor se estenderam de julho a dezembro, com uma maior concentração na área central e na parte Sul do mapa (Figura 4). Para o mencionado ano, observa-se uma tendência de redução das ocorrências de setembro a dezembro, sendo que o mês de agosto se destacou com 31 registros. É importante salientar que não foram identificados focos de calor no período de janeiro a junho, o qual corresponde ao período chuvoso - quando se tem -, e mais úmido nessa porção do Nordeste brasileiro.

De acordo com Souza (2000), no regime pluviométrico do semiárido é grande a variação que se manifesta ao longo do período chuvoso, bem como nos totais anuais das chuvas entre diferentes anos em uma mesma localidade, sendo que a estação chuvosa tem duração de três a cinco meses e o período seco é de sete a nove meses. Destaca-se que o alto e médio curso fluvial do Rio Poti encontra-se engravado na poligonal que representa o semiárido nordestino, o qual exibe um quadro pluviométrico muito variado. 


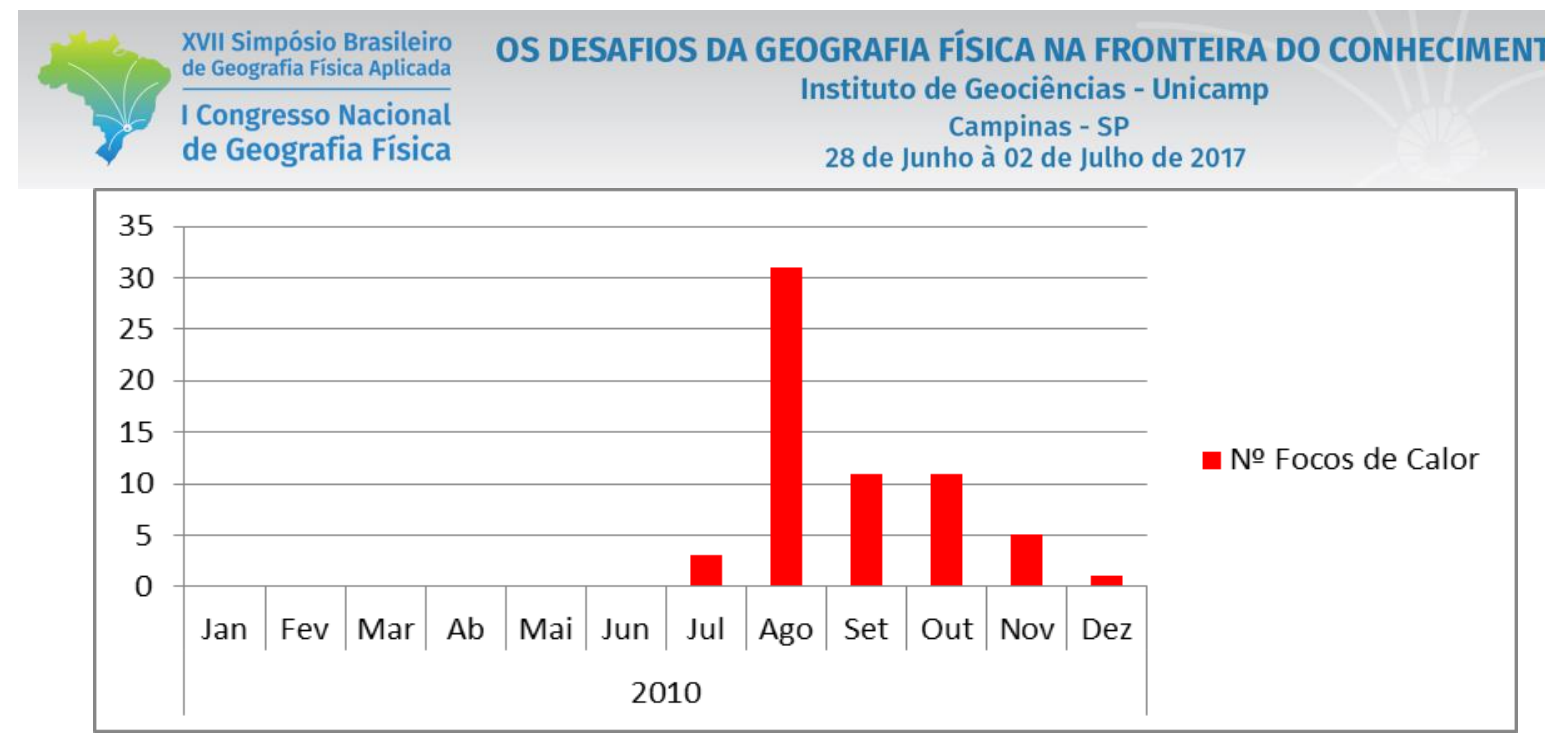

Figura 3 - Número mensal de focos de calor na bacia hidrográfica do Rio Poti em 2010

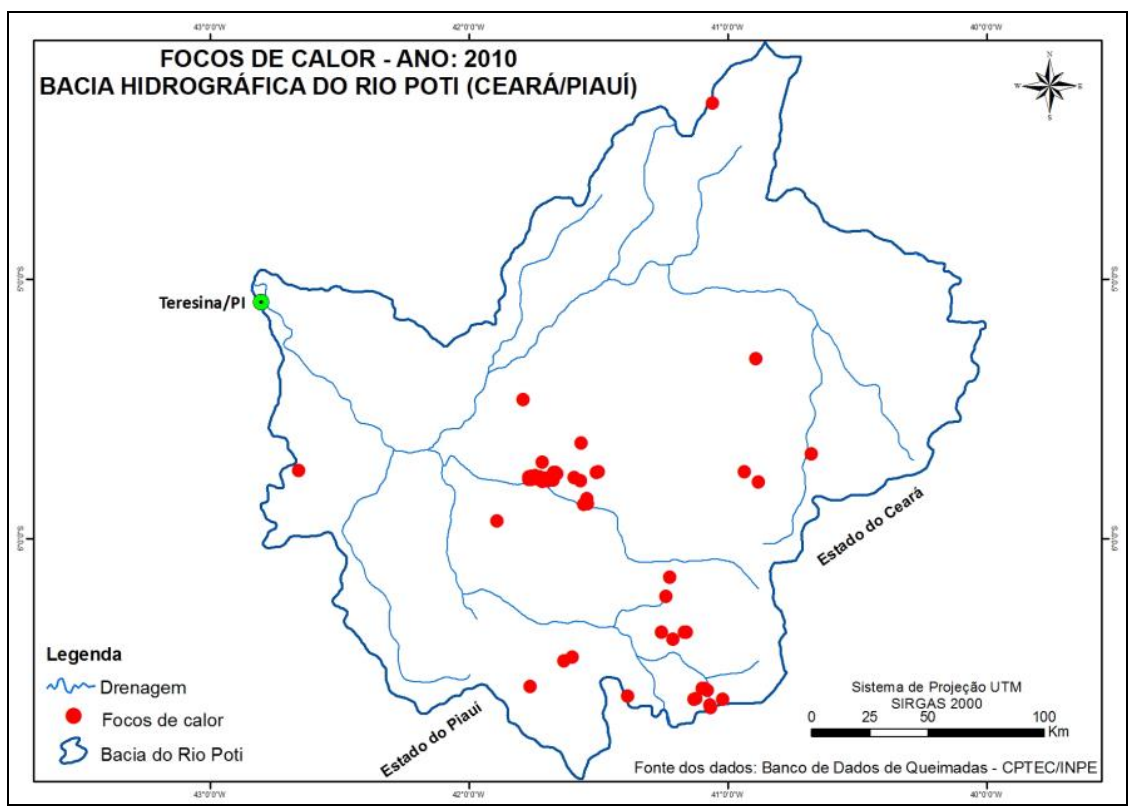

Figura 4 - Focos de calor resistados na bacia hidrográfica do Rio Poti no ano de 2010

Ao analisar o ano de 2013 (Figura 5), verifica-se uma maior concentração dos focos de calor nos meses de agosto a dezembro, sendo que o ápice dos registros foi identificado no mês de outubro, com 226 ocorrências. Ao fazer a comporação com o mapa anterior, corrobora-se uma ampliação significativa e bem distribuída dos focos de calor em toda a bacia hidrográfica, como pode ser visualizado na Figura 6.

É importante observar que houve um aumento notório ao comparar os anos de 2010 e 2013, passando de 62 para 416 registros, respectivamente. Ou seja, um acréscimo de mais de $85 \%$ no número de focos de calor na mesma área territorial. 


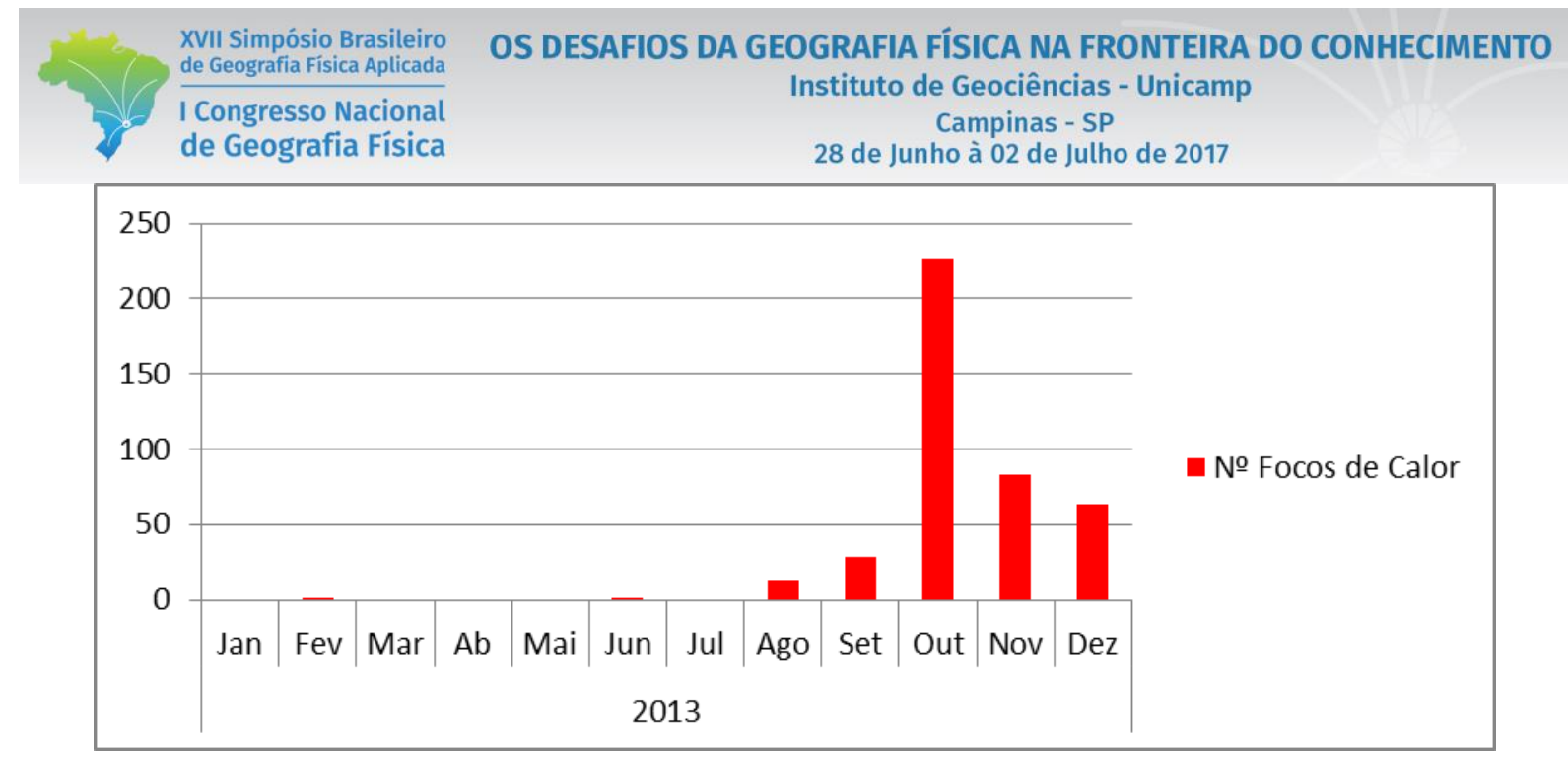

Figura 5 - Número mensal de focos de calor na bacia hidrográfica do Rio Poti em 2013

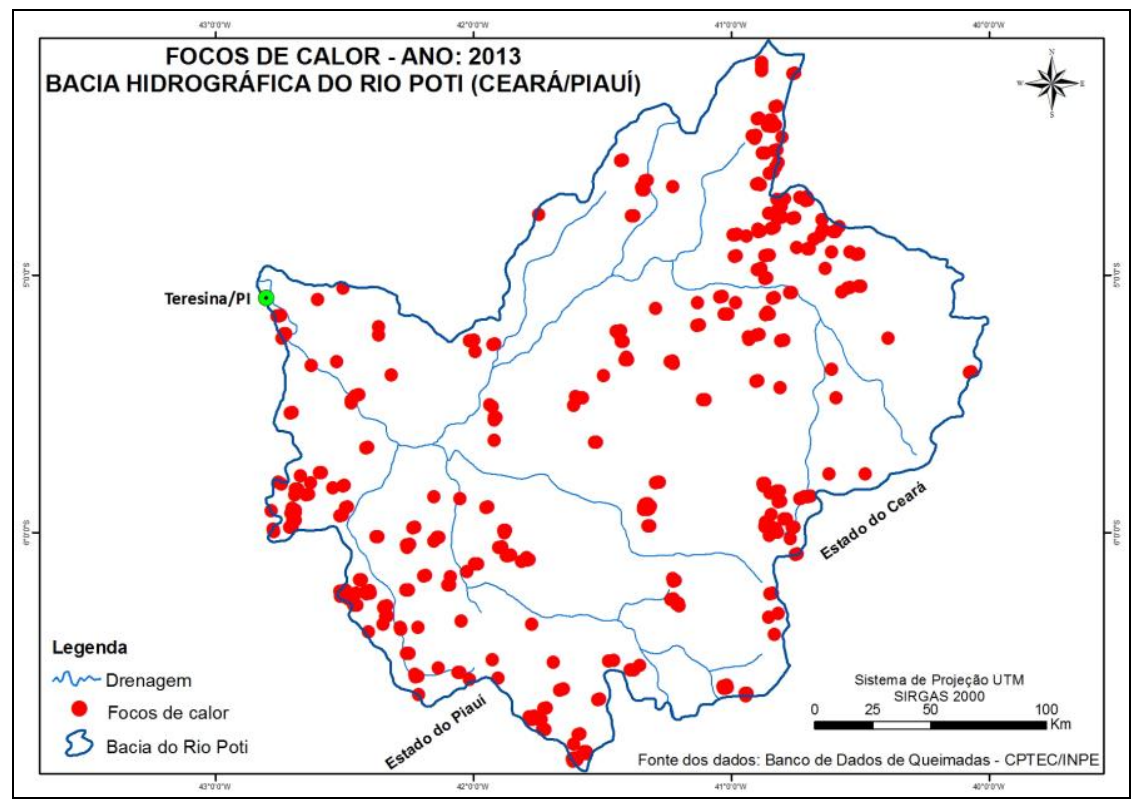

Figura 6 - Focos de calor resistados na bacia hidrográfica do Rio Poti no ano de 2013

O ano de 2016 (Figura 7) é o que mais se destacou dentro do recorte temporal da pesquisa, tendo em vista os elevados registros obtidos. Neste ano foram identificados 1.902 focos de calor na bacia hidrográfica do Rio Poti, sendo que os maiores acontecimentos ocorreram entre os meses de agosto a dezembro, com destaque para o mês de outubro, que registrou 963 ocorrências. Do ponto de vista proporcional, o ano de 2016 superou em mais de $96 \%$ os dados de 2010 e em $78 \%$ o ano de 2013 , ou seja, um aumento muito expressivo para um pequeno lapso temporal. 


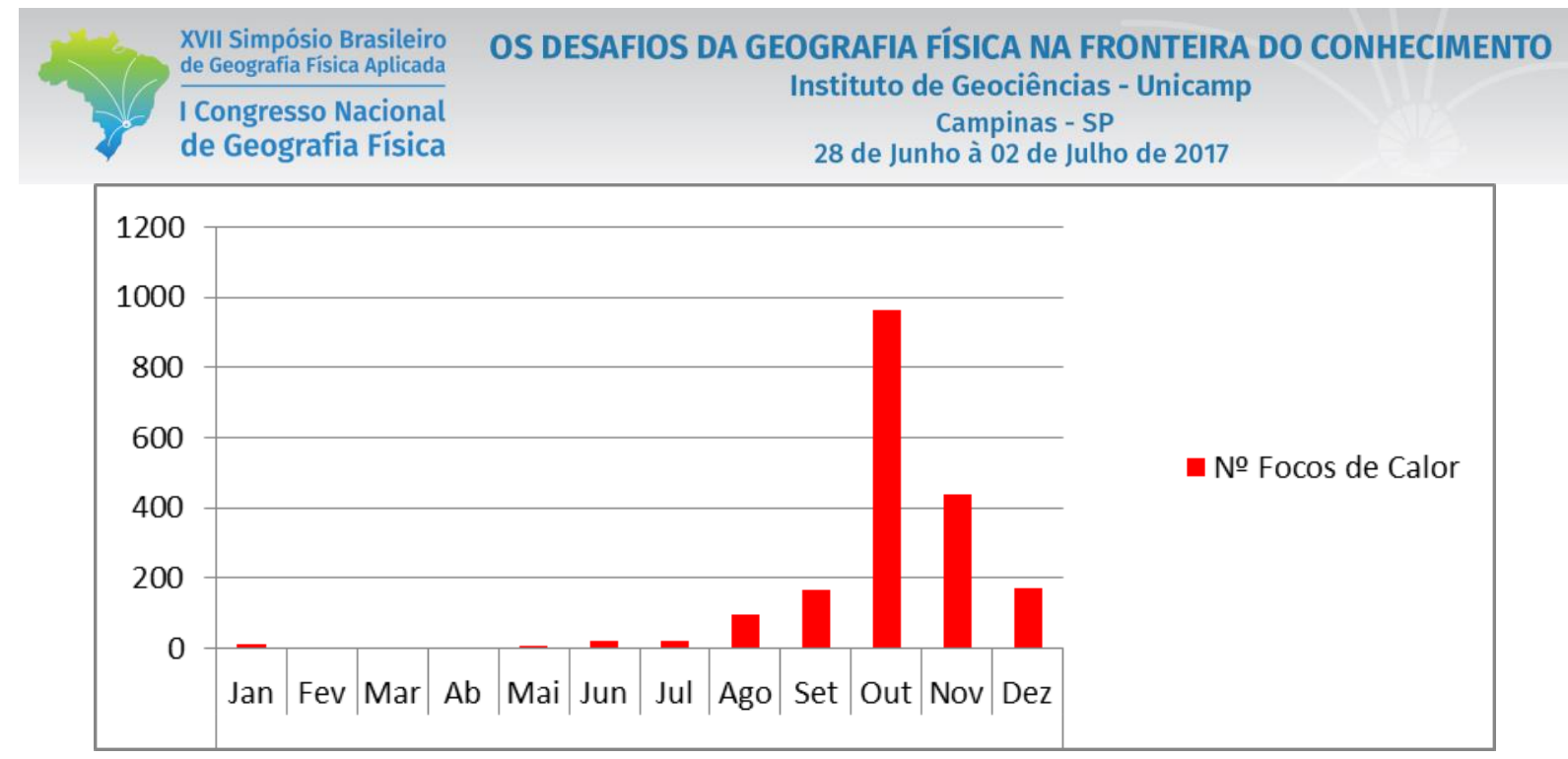

Figura 7 - Número mensal de focos de calor na bacia hidrográfica do Rio Poti em 2016

A espacialização dos focos de calor, do ano de 2016, na bacia hidrográfica em epígrafe, revela uma concentração das ocorrências, sobretudo, na porção Oeste do mapa (Figura 8), contemplando setores do estado do Piauí e, particularmente, em áreas do baixo curso fluvial do Rio Poti.

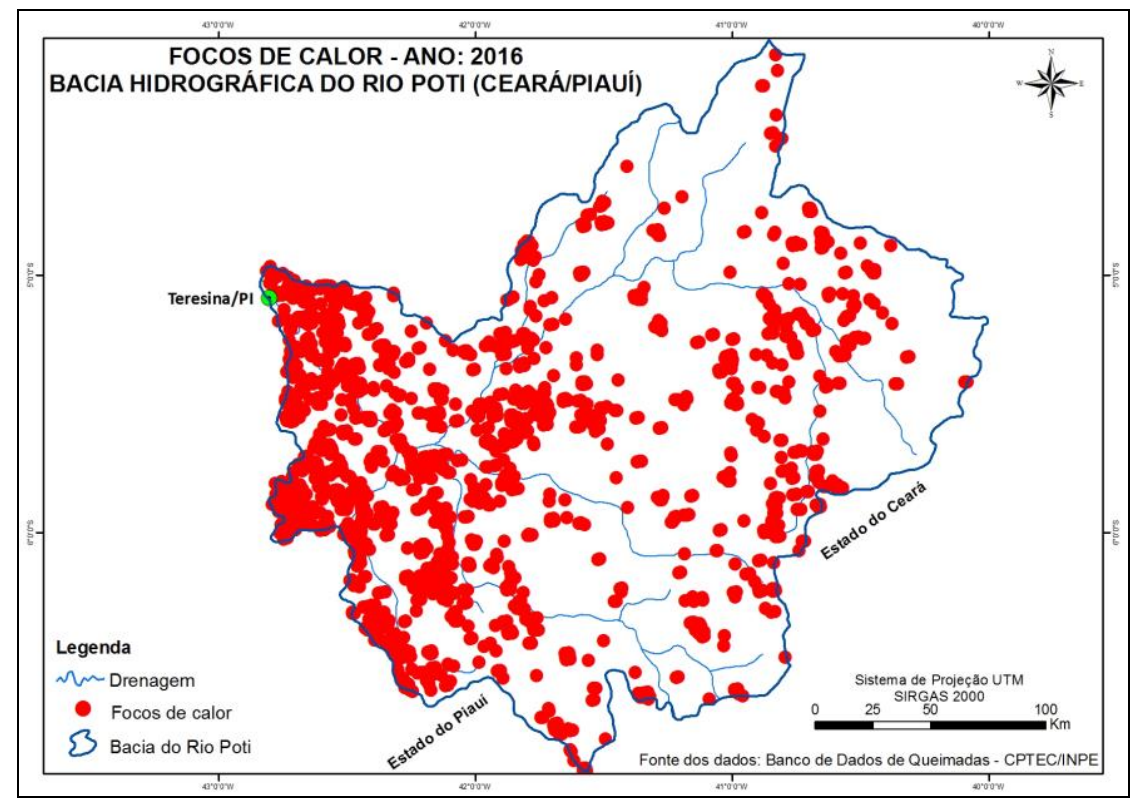

Figura 8 - Focos de calor resistados na bacia hidrográfica do Rio Poti no ano de 2016

Ao considerar os dados agregados (Figura 9), constata-se uma predominância na ocorrência dos focos de calor no segundo semestre do ano (julho a dezembro - 2010/2013/2016), sendo que os maiores registros ocorreram sempre no mês de outubro em todos os anos trabalhados, com respectivamente 62, 416 e 1.902 registros. Em síntese, observa-se uma tendência de aumento das ocorrências a partir do mês de julho, 
atingindo o ápice em outubro, sendo que a partir deste mês, verifica-se uma tendência de queda até dezembro, como é nitidamente retratado na figura seguinte.

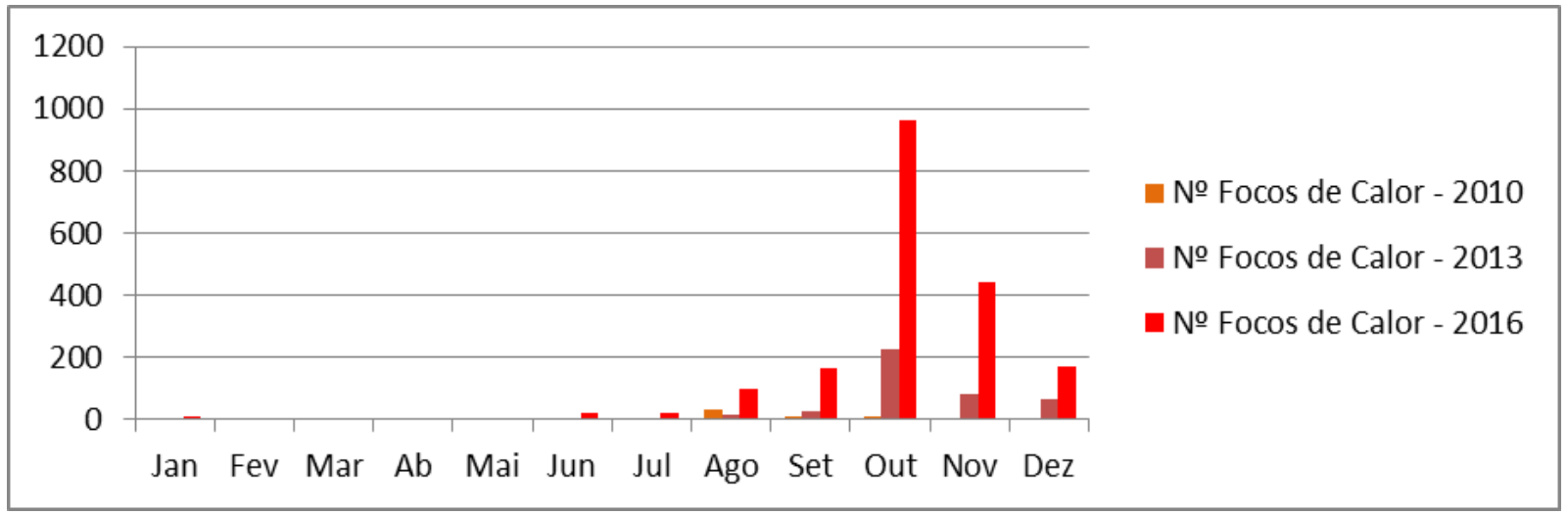

Figura 9 - Focos de calor resistados mensalmente na bacia hidrográfica do Rio Poti nos anos de 2010, 2013 e 2016

Em virtude dos fatores climatológicos, verifica-se que o primeiro semestre do ano (janeiro/junho) é favorecido por melhores condições de umidade, mesmo com totais pluviométricos abaixo da média histórica que tem sido registrado no recorte espacial da pesquisa (Ceará/Piauí), o qual vem derivando secas recorrentes, sobretudo, entre os anos de 2010 e 2016, conforme dados do Centro de Previsão de Tempo e Estudos Climáticos (CPTEC/INPE).

Lima (1982) afirma, em linhas gerais, que a bacia hidrográfica do Rio Poti caracteriza-se por climas quentes, com chuvas de verão (primeiro semestre), apresentando um aumento gradativo de condições de umidade no sentido nascente/foz, por apresentar, à medida que se dirige para oeste, um índice mais significativo de pluviosidade, fruto de um conjunto de fatores atmosféricos e geográficos.

Ao considerar as particularidades termo-pluviométricas do semiárido nordestino e área de entorno, observa-se que a irregularidade temporal e espacial das chuvas, aliada ao registro de elevadas temperaturas por influência de sua tropicalidade, tendem a ser um potencializador para o aumento de incêndios florestais/queimadas, e que são quantificados como focos de calor em sensoriamento remoto, no Nordeste brasileiro.

Mesmo representando um recorte temporal pequeno (2010/2013/2016), é possível configurar um cenário tendencial das ocorrências de focos de calor na bacia hidrográfica do Rio Poti, podendo subsidiar, conforme os dados apresentados, a tomada correta de decisões por parte dos órgãos ambientais competentes do Ceará e Piauí, uma vez que esta bacia hidrográfica drena setores territoriais dos dois Estados. 


\section{Considerações Finais}

A bacia hidrográfica do Rio Poti (Ceará/Piauí) é um importante afluente da Região Hidrográfica do Rio Parnaíba, o qual engloba uma área de aproximadamente $52.270 \mathrm{~km}^{2}$, sendo que $38.797 \mathrm{~km}^{2}$ encontram-se no estado do Piauí e $13.473 \mathrm{~km}^{2}$ no estado do Ceará. Devido a sua extensão e encaixe geológico, o mesmo drena setores do embasamento cristalino Pré-Cambriano e áreas da bacia sedimentar do Parnaíba, configurando algumas particularidades geoambientais.

No que concerne ao objeto e aos objetivos almejados, foram identificados 2.380 focos de calor obtidos pelo satélite NOAA-18, através do sensor AVHRR, para os anos de 2010, 2013 e 2016, com respectivamente 62, 416 e 1.902 registros, totalizando um percentual progressivo de mais de $97 \%$ no número de ocorrências entre o primeiro e o último ano da pesquisa.

Ao considerar o recorte espacial, o ano de 2010 foi o que obteve os menores registros, sendo que as ocorrências dos focos de calor se estenderam de julho a dezembro, com uma maior concentração na área central e na parte Sul da bacia hidrográfica. Em 2013, verifica-se uma maior concentração dos focos de calor nos meses de agosto a dezembro, sendo que os registros ficaram concentrados nos setores Norte e Oeste da bacia. Por sua vez, o ano de 2016 foi o que mais se destacou, sendo que os maiores acontecimentos ocorreram também no segundo semestre do ano. Não obstante, houve neste ano uma maior distribuição espacial dos focos de calor em toda a extensão da bacia hidrográfica do Rio Poti.

Em síntese, constatou-se que os registros encontram-se agrupados, sobretudo, no segundo semestre do ano (julho a dezembro), sendo que as maiores incidências de focos de calor, no recorte temporal adotado,

concentraram-se no mês de outubro, com respectivamente 11, 226 e 963 focos. É importante salientar que no primeiro semestre do ano (janeiro a junho), os dados são insignificantes, uma vez que este corresponde ao período chuvoso e/ou mais úmido nessa porção do Nordeste brasileiro.

Com base nos dados e considerando o processo histórico de uso e ocupação da terra na Região Nordeste, é possível afirmar que esta concentração de focos de calor no segundo semestre do ano se dá em virtude, sobretudo, da tradição secular do preparo da terra para o plantio no ano vindouro, em que a limpeza do terreno é sequenciada pela queima.

É válido lembrar que os registros obtidos não contempla a quantidade exata de queimadas que existiram in loco, tendo em vista que a presença de nuvens e o sombreamento das árvores podem interferir diretamente na detecção dos focos calor, associada ainda as características de resolução (espacial, temporal, espectral e radiométrica) do satélite/sensor utilizado. Não obstante, esse cenário é o que mais se aproxima da realidade das ocorrências de focos de calor registrados na bacia hidrográfica em epígrafe. 


\section{Bibliografia}

ALBUQUERQUE, E. L. S.; LIMA, I. M. M. F. Análise dos sistemas ambientais no alto curso da bacia hidrográfica do Rio Poti, Estado do Ceará. In: XI Simpósio Nacional de Geomorfologia - SINAGEO, 11, 2016. Maringá-PR. Anais... Maringá-PR: SINAGEO, 2016.

ASSAD, E. D.; SANO, E. E. Sistemas de informações geográficas. Aplicações na agricultura. 2a . ed, Brasília: EMBRAPA, 1998.

BRASIL. Instituto Nacional de Pesquisas Espaciais - INPE. Dados pontuais de focos de calor. Programa de Monitoramento de Focos. <http://sigma.cptec.inpe.br/queimadas/>. Acesso em: 01/02/2017.

FERREIRA, N. J. (Org.). Aplicações Ambientais Brasileiras dos Satélites NOAA e TIROS-N. São Paulo: Oficina de Textos, 2004.

FLORENZANO, T. G. Iniciação em sensoriamento remoto. 2. ed. São Paulo: Oficina de Textos, 2007.

GOMES, D. D. M.; MEDEIROS, C. N. de; ALBUQUERQUE, E. L. S. Análise têmporo-espacial das ocorrências de focos de calor no estado do Ceará: configuração dos cenários no contexto das unidades fitogeográficas e das Macrorregiões de Planejamento. Texto para Discussão, Fortaleza, nº. 90, 01-28, dez. 2010.

JENSEN, J. R. Sensoriamento Remoto do Ambiente. 1 1a edição. São José dos Campos: Ed. Parêntese, 2009.

LIMA, I. M. M. F. Caracterização Geomorfológica da Bacia Hidrográfica do Poti. (Dissertação de Mestrado). Programa de Pós-Graduação em Geografia. UFRJ, Rio de Janeiro, 1982.

NOVO, E. M. L. M. Sensoriamento Remoto: princípios e aplicações. $2^{\mathrm{a}}$. ed, São Paulo: EDITORA EDGARD BLÜCHER LTDA., 1998.

PFALTZGRAFF, P. A. S.; TORRES F. S. M.; BRANDÃO, R. L. (Orgs.). Geodiversidade do estado do Piauí. Recife: CPRM, 2010.

PIAUÍ. Secretaria do Meio Ambiente e Recursos Hídricos. Plano Estadual de Recursos Hídricos - Relatório Síntese. Teresina/PI: SEMAR, 2010.

ROCHA, C. H. B. Geoprocessamento: tecnologia transdisciplinar. Juiz de Fora: Ed. do Autor, 2000.

SILVA FILHO, E. B. da; TELES, L. J. S; SANTOS NETO, L. A. dos. Ocorrências de focos de calor no estado de Rondônia em 2007. Sociedade \& Natureza, Uberlândia, 21 (2): 123-140, ago. 2009.

SOUZA, M. J. N. Bases naturais e esboço do zoneamento geoambiental do estado do Ceará. In: SOUZA, M. J. N; LIMA, L. C.; MORAIS, J. O. (Org.) Compartimentação territorial e gestão regional do Ceará. Fortaleza: Ed. FUNECE, 2000.

ZANELLA, M. E; OLIMPIO, J. L. S; COSTA, M. C. L; DANTAS, E. W. C. Vulnerabilidade socioambiental do Baixo curso da Bacia Hidrográfica do Rio Cocó, Fortaleza-CE. Revista Sociedade e Natureza, n 25 , v. 2 , p. 317 $332,2013$.

\section{Agradecimentos}

À Universidade Federal do Piauí (UFPI), por meio da Coordenação do Curso de Geografia - CCG/CCHL, em possibilitar o desenvolvimento do Projeto de Pesquisa intitulado - Análise Geoambiental e Mapeamento das Áreas Degradadas na Bacia Hidrográfica do Rio Poti: Geoprocessamento Aplicado ao Manejo e Conservação dos Recursos Naturais. 